\title{
Effects of environmental conditions on reproductive effort and nest success of Arctic-breeding shorebirds
}

EMILY L. WEISER, ${ }^{1, *}$ ID STEPHEN C. BROWN ${ }^{2}$ RICHARD B. LANCTOT, ${ }^{3}$ H. RIVER GATES $, 2,3,4$ KENNETH F. ABRAHAM, ${ }^{5}$ REBECCA L. BENTZEN, ${ }^{6}$ JOËL BÊTY, ${ }^{7}$ MEGAN L. BOLDENOW, ${ }^{8}$

RODNEY W. BROOK, ${ }^{5}$ TYRONE F. DONNELLY, ${ }^{9}$ WILLOW B. ENGLISH, ${ }^{10}$ SCOTT A. FLEMMING, ${ }^{11}$ SAMANTHA E. FRANKS,${ }^{12}$ H. GRANT GILCHRIST, ${ }^{13}$ MARIE-ANDRÉE GIROUX,${ }^{7,14}$ ANDREW JOHNSON, ${ }^{15}$ STEVE KENDALL, ${ }^{16,17}$ LISA V. KENNEDY,${ }^{11}$ LAURA KOLOSKI, ${ }^{11}$ EUNBI KWON,${ }^{1,18}$ JEAN-FRANÇOIS LAMARRE, ${ }^{7}$ DAVID B. LANK, ${ }^{19}$ CHRISTOPHER J. LATTY, ${ }^{16}$ NICOLAS LECOMTE, ${ }^{20}$ JOSEPH R. LIEBEZEIT, ${ }^{21}$ LAURA MCKINNON,${ }^{22,23}$ ERICA NOL, ${ }^{11}$ JOHANNA PERZ, ${ }^{11}$ JENNIE RAUSCH, ${ }^{24}$ MARTIN ROBARDS, ${ }^{6}$ SARAH T. SAALFELD, ${ }^{3}$ NATHAN R. SENNER, ${ }^{25,15}$ PAUL A. SMITH, ${ }^{13}$ MIKHAIL SOLOVIEV, ${ }^{26}$ DIANA SOLOVYEVA, ${ }^{27}$ DAVID H. WARD, ${ }^{9}$ PAUL F. WOODARD ${ }^{24}$ \& BRETT K. SANDERCOCK ${ }^{1}$ ${ }^{1}$ Division of Biology, Kansas State University, Manhattan, KS, USA

${ }^{2}$ Manomet Center for Conservation Sciences, Manomet, MA, USA

${ }^{3}$ US Fish and Wildlife Service, Anchorage, AK, USA

${ }^{4}$ Audubon Alaska, Anchorage, AK, USA

${ }^{5}$ Ontario Ministry of Natural Resources and Forestry, Peterborough, ON, Canada

${ }^{6}$ Wildlife Conservation Society, Arctic Beringia Program, Fairbanks, AK, USA

${ }^{7}$ Département de Biologie, Chimie et Géographie and Centre d'Études Nordiques, Université du Québec à Rimouski, Rimouski, QC, Canada

${ }^{8}$ Department of Biology and Wildlife, University of Alaska Fairbanks, Fairbanks, AK, USA

${ }^{9}$ US Geological Survey, Anchorage, AK, USA

${ }^{10}$ Department of Biological Sciences, Simon Fraser University, Burnaby, BC, Canada

${ }^{11}$ Environmental and Life Sciences Graduate Program, Trent University, Peterborough, ON, Canada

${ }^{12}$ British Trust for Ornithology, Thetford, UK

${ }^{13}$ Environment and Climate Change Canada, Ottawa, ON, Canada

${ }^{14}$ K.-C.-Irving Research Chair in Environmental Sciences and Sustainable Development, Département de Chimie et de Biochimie, Université de Moncton, Moncton, NB, Canada

${ }^{15}$ Cornell Lab of Ornithology, Cornell University, Ithaca, NY, USA

${ }^{16}$ US Fish and Wildlife Service, Arctic National Wildlife Refuge, Fairbanks, AK, USA

${ }^{17}$ US Fish and Wildlife Service, Hakalau Forest National Wildlife Refuge, Hilo, HI, USA

${ }^{18}$ Department of Fish and Wildlife Conservation, Virginia Tech, Blacksburg, VA, USA

${ }^{19}$ Centre for Wildlife Ecology, Simon Fraser University, Burnaby, BC, Canada

${ }^{20}$ Canada Research Chair in Polar and Boreal Ecology, Université de Moncton, Moncton, NB, Canada

${ }^{21}$ Audubon Society of Portland, Portland, OR, USA

${ }^{22}$ Department of Multidisciplinary Studies/Biology, York University Glendon Campus, Toronto, ON, Canada

${ }^{23}$ Department of Multidisciplinary Studies/Biology, York University Glendon Campus, Peterborough, ON, Canada

${ }^{24}$ Environment and Climate Change Canada, Yellowknife, NT, Canada

${ }^{25}$ Division of Biological Sciences, University of Montana, Missoula, MT, USA

${ }^{26}$ Lomonosov Moscow State University, Moscow, Russia

${ }^{27}$ Institute of Biological Problems of the North, Magadan, Russia

The Arctic is experiencing rapidly warming conditions, increasing predator abundance, and diminishing population cycles of keystone species such as lemmings. However, it is still not known how many Arctic animals will respond to a changing climate with altered trophic interactions. We studied clutch size, incubation duration and nest survival of 17 taxa of Arctic-breeding shorebirds at 16 field sites over 7 years. We predicted that physiological benefits of higher temperatures and earlier snowmelt would increase reproductive effort and nest survival, and we expected increasing predator abundance and 
decreasing abundance of alternative prey (arvicoline rodents) to have a negative effect on reproduction. Although we observed wide ranges of conditions during our study, we found no effects of covariates on reproductive traits in 12 of 17 taxa. In the remaining taxa, most relationships agreed with our predictions. Earlier snowmelt increased the probability of laying a full clutch from 0.61 to 0.91 for Western Sandpipers, and shortened incubation by 1.42 days for arcticola Dunlin and 0.77 days for Red Phalaropes. Higher temperatures increased the probability of a full clutch from 0.60 to 0.93 for Western Sandpipers and from 0.76 to 0.97 for Red-necked Phalaropes, and increased daily nest survival rates from 0.9634 to 0.9890 for Semipalmated Sandpipers and 0.9546 to 0.9880 for Western Sandpipers. Higher abundance of predators (foxes) reduced daily nest survival rates only in Western Sandpipers (0.9821-0.9031). In contrast to our predictions, the probability of a full clutch was lowest (0.83) for Semipalmated Sandpipers at moderate abundance of alternative prey, rather than low abundance $(0.90)$. Our findings suggest that in the short-term, climate warming may have neutral or positive effects on the nesting cycle of most Arctic-breeding shorebirds.

Keywords: climate change, clutch size, incubation duration, nest survival, waders.

Anthropogenic changes in climate and ecosystems have been pronounced in the Arctic. Average temperatures are increasing by $0.25-1.1{ }^{\circ} \mathrm{C}$ per decade and the timing of spring snowmelt is advancing by 1-3 days per decade (Stone et al. 2002, ACIA 2004; Gauthier et al. 2013). Mean summer temperatures are expected to further increase by $1-4{ }^{\circ} \mathrm{C}$ by the end of the 21 st century, and a combination of higher temperatures and declining snow accumulation will result in snowmelt occurring even earlier in the spring (IPCC 2013, RCP4.5 scenario).

Climatic variables are key drivers of phenology in Arctic ecosystems. Animals at lower trophic levels are strongly affected by weather, with timing of snowmelt driving the annual pulse of invertebrate emergence (Tulp \& Schekkerman 2008). The abundance of invertebrate prey at high latitudes is a critical food resource to fuel reproduction and rapid growth of offspring for consumers at intermediate trophic levels (Schekkerman et al. 2003, Meltofte et al. 2007, Tulp \& Schekkerman 2008). In years of early snowmelt, invertebrate prey become available earlier, allowing insectivorous birds to lay eggs soon after arrival on the breeding grounds (Klaassen et al. 2001, Meltofte et al. 2007, Sénéchal et al. 2011). In contrast, breeding is delayed in years with later snowmelt (Meltofte et al. 2008, Liebezeit et al. 2014), and

*Corresponding author.

Email: Emily.L.Weiser@gmail.com late-breeding birds have lower reproductive success, including smaller clutch sizes and lower nest survival (Weiser et al. 2017). As snowmelt advances, Arctic-breeding birds may therefore experience better conditions for egg-laying and incubation as a result of earlier food availability (Fig. 1).

Higher summer temperatures may also provide advantages for Arctic birds. Like early snowmelt, higher temperatures promote emergence and activity of invertebrate prey, increasing availability of food for birds (Meltofte et al. 2007, Bolduc et al. 2013). Higher temperatures can also reduce the duration and energetic cost of incubation, especially in species with uniparental care of the clutch (Piersma et al. 2003, Reneerkens et al. 2011), and have been shown to improve chick growth rates (McKinnon et al. 2013). A warming climate may therefore improve breeding performance for some Arctic-breeding birds, especially small-bodied species that rely on Arctic food sources to provision eggs (Fig. 1; Klaassen et al. 2001). However, chick survival is also linked to the timing of emergence and abundance of invertebrate prey, so reproductive output could be reduced for species that do not shift their breeding phenology to match changes in prey availability (Hill 2012, Senner et al. 2017). Any negative effects of climate change would probably exacerbate the impacts of ongoing loss of breeding habitat (Lin et al. 2012, Ballantyne \& Nol 2015, Wauchope et al. 2017). 


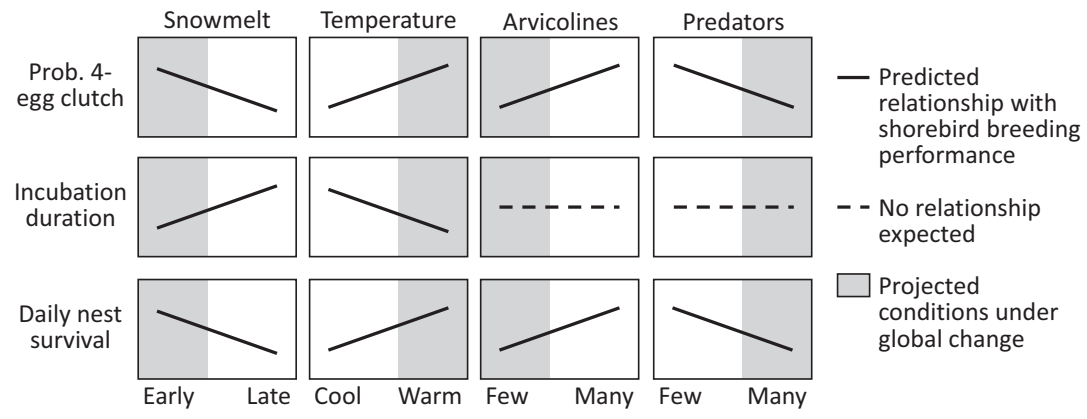

Figure 1. Predicted relationships between three components of the nesting cycle of Arctic-breeding shorebirds (rows) and four environmental and ecological covariates (columns). Predictions were based on physiological effects and trophic interactions (solid lines). A flat dashed line indicates no expected relationship.

Biological communities in the Arctic are also changing. Population cycles of arvicoline (formerly microtine) rodents, primarily lemmings and voles, drive many of the trophic interactions in Arctic ecosystems. The alternative prey hypothesis predicts that in years of high arvicoline abundance, alternative prey species such as birds benefit from lower predation pressure, resulting in higher reproductive success (Angelstam et al. 1984, Summers et al. 1998). Climate change is reducing the amplitude and periodicity of arvicoline population cycles at some Arctic sites (Kausrud et al. 2008, Gilg et al. 2009), so predation pressure on breeding birds is probably becoming more consistent, reducing the frequency of highly successful years that help to bolster the populations of Arctic birds. Evidence for the alternative prey hypothesis has primarily been drawn from the Palearctic, so it remains unclear whether the reproductive success of Nearctic birds may be affected by arvicoline abundance (McKinnon et al. 2014).

Predator communities are also changing across the Arctic as a result of increasing abundance and range expansion of generalist predators such as gulls and foxes that benefit from human activities (NAS 2003; Killengreen et al. 2011, Stehn et al. 2013, Stickney et al. 2014). Increasing abundance and diversity of generalist predators and possible declines in abundance of alternative prey could reduce nest success of Arctic-breeding birds that benefit from low predator densities at high latitudes (Fig. 1; Sovada et al. 2001, Liebezeit et al. 2009, McKinnon et al. 2010). A higher risk of nest predation may be associated not only with reduced nest success, but also with reduced clutch sizes if female shorebirds use a bet-hedging strategy to adjust reproductive effort based on the expected probability of nest success (Fig. 1; Drent \& Daan 1980, Lima 1987).

Arctic birds at intermediate trophic levels may therefore be particularly vulnerable to climate change, as they will be affected by environmental and ecological changes that have either top-down or bottom-up effects. Migratory shorebirds make up a high proportion of the vertebrate community in the Arctic and may be particularly susceptible to the effects of environmental and ecological changes due to their use of key sites in multiple geographical regions (Piersma \& Lindström 2004, Thomas et al. 2006). Many species of shorebirds are experiencing population declines, in part because of habitat loss and degradation at important migratory stopover sites (Andres et al. 2012, Studds et al. 2017). It is unclear whether changes at breeding sites are also playing a role in the ongoing population declines, but some evidence indicates that changes may be affecting shorebird fecundity. Seasonal declines in reproductive performance have been widely observed, but it is unclear whether the seasonality is driven by temporal constraints or environmental conditions (Sandercock et al. 1999, Smith \& Wilson 2010, Weiser et al. 2017). As in other Arctic birds, components of fecundity in shorebirds can be affected by temperature, timing of snowmelt, abundance of arvicoline rodents, and predator abundance or activity (Nol et al. 1997, Summers et al. 1998, Blomqvist et al. 2002, McKinnon et al. 2013, Jamieson et al. 2014, Kwon 2016). However, due to the logistical challenges of working at remote field sites, most previous studies have been limited to single study sites, which can produce estimates of fecundity or effects of covariates that are affected by local conditions and may not be representative of the entire 
range of the species (McCaffery \& Ruthrauff 2004, Senner et al. 2017). Estimates of effects of environmental and ecological covariates on shorebird breeding performance from a broad geographical scale are needed to evaluate how these vulnerable species may be affected by climate change.

The Arctic Shorebird Demographics Network (ASDN) implemented standardized field protocols to study shorebird ecology at a distributed network of sites in Arctic Alaska, Canada and Russia (Lanctot et al. 2015). Here, we tested for effects of environmental and ecological covariates that could affect clutch size, incubation duration and daily survival rate (DSR) of nests through physiological effects or trophic interactions (Fig. 1). First, we predicted that physiological effects of early snowmelt and higher temperatures would result in (1) larger clutch sizes, especially for smaller species of shorebirds that are primarily income breeders, and (2) shorter incubation periods and higher DSR, especially for species with uniparental care of the nest. Secondly, we expected that lower abundance of arvicoline rodents and higher abundance of predators would increase the risk of nest predation and thus be associated with smaller clutches and lower DSR for all shorebird species. Our study is the first to use nesting data from across the geographical distribution of 17 taxa of Arctic-breeding shorebirds, providing comprehensive estimates of the effects of environmental conditions on demographic rates of a vulnerable group of Arctic birds.

\section{METHODS}

We monitored breeding shorebirds, environmental covariates and ecological covariates for up to 7 years at 16 field sites in Arctic and subarctic North America (Fig. 2; Table S1). In 2010-2014, all sites implemented a common set of field protocols and data formats developed for the ASDN (Brown et al. 2014). At three sites (NOME, BARR, BYLO), additional data were collected with similar field methods in 2008 and 2009 (McKinnon \& Bêty 2009, English et al. 2014, Saalfeld \& Lanctot 2015). Fourteen species of shorebirds commonly nested at our study sites, with body masses ranging from 26 to $381 \mathrm{~g}$ and a mix of biparental and uniparental incubation strategies (Table 1). Four allopatric subspecies of Dunlin occurred in our study area: sakhalina, pacifica, arcticola and hudsonia, with no recognized subspecific variation in the other 13 species (Cramp \&
Simmons 1983, Miller et al. 2015). We focused on three major components of reproductive output in our analysis: clutch size, incubation duration and daily nest survival.

\section{Shorebird data}

Field methods for monitoring shorebirds are described in detail by Brown et al. (2014) and Weiser et al. (2017). In brief, we located shorebird nests by observing bird behaviour, systematically walking the tundra or rope-dragging, and estimated the age of each nest upon discovery using the flotation method (Liebezeit et al. 2007). We recorded the clutch size at discovery and on subsequent visits, and when the number of eggs did not increase for $>2$ days while the nest was active (i.e. not failed), we considered that number to be the final clutch size. Only $8 \%$ of nests with a full fouregg clutch lost an egg during incubation, so the observed final clutch size should match the actual clutch size in nearly all cases (Weiser et al. 2017). We assumed that clutches with more than four eggs $(0.3 \%$ of all nests) resulted from anomalous joint egg-laying by multiple females (Arnold 1999) and excluded those nests from all analyses.

We monitored each nest daily during egg-laying, every $2-5$ days during incubation, and daily starting 4 days before the expected hatch date. We recorded the final nest fate as hatched, failed or unknown. We recorded a nest as hatched if at least one newly hatched chick was observed at the nest or if eggshell fragments indicative of hatching were found in the nest within 4 days of the expected hatch date (Mabee 1997, Brown et al. 2014). We considered nest failure to be due to predation when all eggs disappeared $>4$ days before the predicted hatch date or when large fragments of eggshells were present in the nest. We considered a nest to have failed due to abandonment when eggs were left unattended by parents for three or more visits. Other infrequent causes of failure each affected $<2 \%$ of nests and were pooled in our analysis. We captured and individually marked parents attending nests and recorded morphometrics for related studies.

For nests that were found during egg-laying and survived to hatch, we calculated the duration of incubation as the time from the day the last egg was laid until the day the first egg hatched. To evaluate daily nest survival, we generated an encounter history for each nest using the day the 


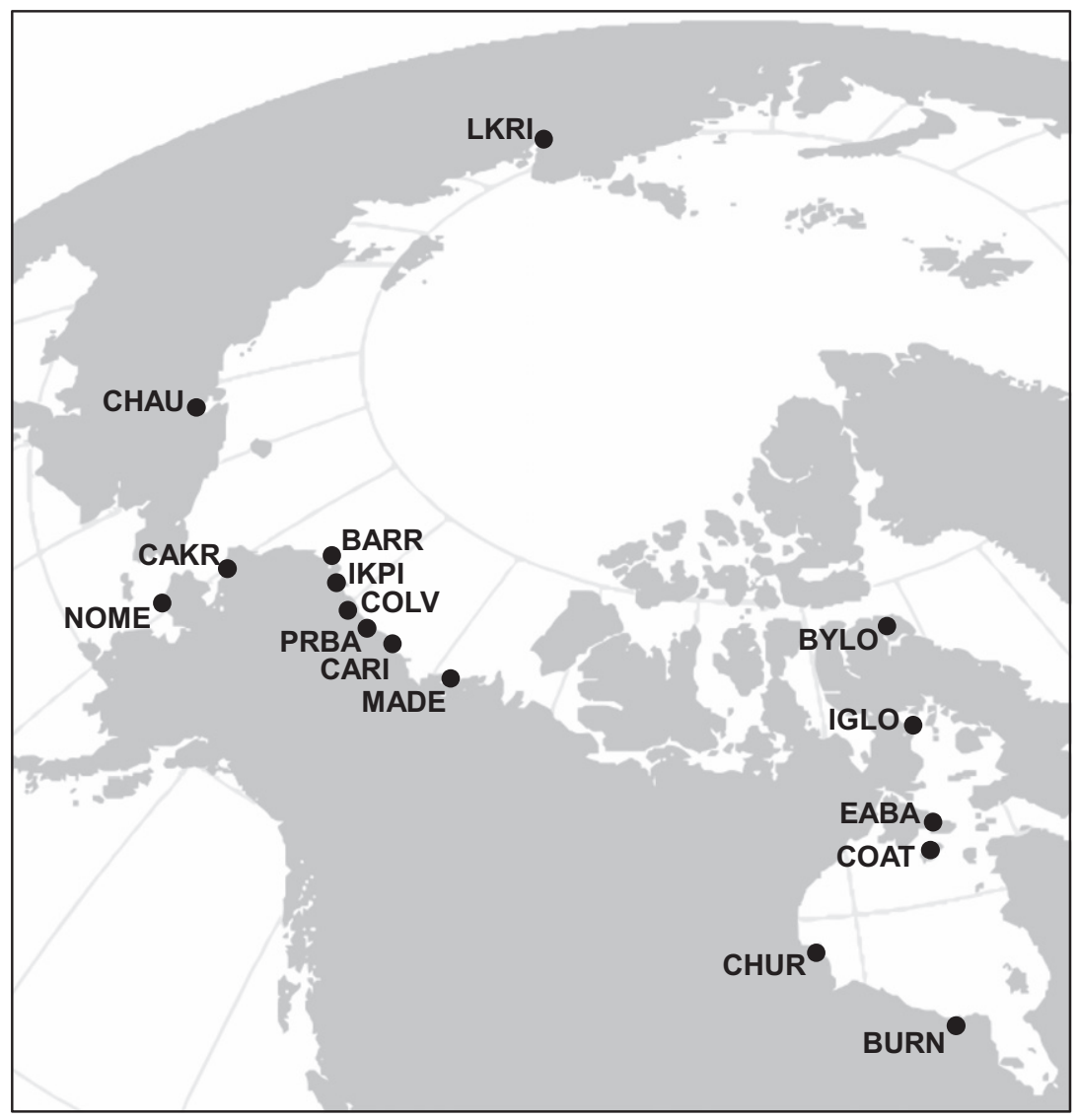

Figure 2. Locations of 16 study sites in the Arctic Shorebird Demographics Network in Russia, Alaska and Canada, $2008-2014$. Complete names and geographical coordinates of the field sites are provided in Table S1.

nest was found, the last day it was observed alive and the day it was observed to have failed. If there was a gap in monitoring between the last day the nest was observed alive and the first day it was observed to have failed, we used the midpoint between the two dates as the date of failure. We restricted each analysis to the subset of species with $\geq 30$ nests for which we had complete data for all of our environmental and ecological covariates. We analysed each of the four subspecies of Dunlin separately, for a total of 17 taxa in the analysis (Table 1).

\section{Environmental and ecological covariates}

We recorded two environmental variables, the annual timing of snowmelt and hourly ambient temperature, and two ecological variables, the daily abundance of alternative prey and predators.
We used daily satellite data with a resolution of $4 \mathrm{~km}$ to estimate the ordinal date on which snowmelt was complete at each field site (i.e. all land and water was free of snow and ice; National Ice Center 2008), which served as an index for spring phenology. We recorded the timing of snowmelt at each site as the first date when the grid cell containing the field camp was categorized as 'land' based on a combination of visible imagery, spectrometry and microwave data (National Ice Center 2008). Estimates from satellite imagery were positively correlated with field observations for nine sites (1-4 years each) where field crews arrived before snowmelt was complete $(r>0.65)$.

We calculated daily mean temperatures from hourly data recorded by permanent weather stations near our study sites (Government of Canada 2015; National Centers for Environmental Information 2015; CEN 2016) or by automated portable weather stations at remote field camps (Onset 
Table 1. Shorebird taxa included in our analyses of effects of environmental covariates on components of fecundity. Species are ordered by taxonomy following Clements et al. (2015), and subspecies of Dunlin are ordered by their breeding range (west to east).

\begin{tabular}{|c|c|c|c|c|c|c|c|c|c|c|}
\hline \multirow[b]{2}{*}{$\begin{array}{l}\text { Common } \\
\text { name }\end{array}$} & \multirow[b]{2}{*}{$\begin{array}{l}\text { Scientific } \\
\text { name }\end{array}$} & \multirow[b]{2}{*}{ Code } & \multirow[b]{2}{*}{ Incubation $^{a}$} & \multirow{2}{*}{$\begin{array}{c}\text { Mean } \\
\text { body } \\
\text { mass }(g)^{b}\end{array}$} & \multicolumn{2}{|c|}{ Clutch size } & \multicolumn{2}{|c|}{ Incubation duration } & \multicolumn{2}{|c|}{$\begin{array}{l}\text { Apparent nest } \\
\text { survival }\end{array}$} \\
\hline & & & & & $\begin{array}{l}\text { Mean } \pm \text { sd } \\
\text { (no. of eggs) }\end{array}$ & $n$ & $\begin{array}{l}\text { Median } \pm \text { sd } \\
\text { (days) }\end{array}$ & $n$ & $\begin{array}{l}\text { Prop. } \\
\text { hatched }\end{array}$ & $n$ \\
\hline Grey Plover & $\begin{array}{l}\text { Pluvialis } \\
\text { squatarola }\end{array}$ & BBPL & MF & 195 & $3.87 \pm 0.37$ & 94 & - & - & 0.49 & 53 \\
\hline $\begin{array}{l}\text { American } \\
\text { Golden } \\
\text { Plover }\end{array}$ & $\begin{array}{l}\text { Pluvialis } \\
\text { dominica }\end{array}$ & AMGP & MF & 147 & $3.92 \pm 0.34$ & 485 & - & - & 0.52 & 148 \\
\hline $\begin{array}{l}\text { Semipalmated } \\
\text { Plover }\end{array}$ & $\begin{array}{l}\text { Charadrius } \\
\text { semipalmatus }\end{array}$ & SEPL & MF & 47 & $3.29 \pm 1.15$ & 59 & - & - & 0.62 & 36 \\
\hline Whimbrel & $\begin{array}{l}\text { Numenius } \\
\text { phaeopus }\end{array}$ & WHIM & MF & 381 & $3.58 \pm 0.82$ & 138 & - & - & 0.47 & 80 \\
\hline $\begin{array}{l}\text { Ruddy } \\
\text { Turnstone }\end{array}$ & $\begin{array}{l}\text { Arenaria } \\
\text { interpres }\end{array}$ & RUTU & MF & 106 & $3.76 \pm 0.65$ & 81 & - & - & 0.53 & 44 \\
\hline \multirow[t]{4}{*}{ Dunlin ${ }^{c}$} & $\begin{array}{l}\text { Calidris alpina } \\
\text { sakhalina }\end{array}$ & DUNLsak & MF & 54 & $3.85 \pm 0.43$ & 68 & - & - & - & - \\
\hline & $\begin{array}{c}\text { Calidris a. } \\
\text { pacifica }\end{array}$ & DUNLpac & MF & 55 & $3.85 \pm 0.39$ & 79 & - & - & 0.61 & 53 \\
\hline & $\begin{array}{c}\text { Calidris a. } \\
\text { arcticola }\end{array}$ & DUNLarc & MF & 58 & $3.96 \pm 0.22$ & 480 & $21 \pm 2.34$ & 33 & 0.67 & 302 \\
\hline & $\begin{array}{l}\text { Calidris a. } \\
\text { hudsonia }\end{array}$ & DUNLhud & MF & 57 & $3.86 \pm 0.46$ & 136 & - & - & 0.73 & 84 \\
\hline $\begin{array}{l}\text { Baird's } \\
\text { Sandpiper }\end{array}$ & Calidris bairdii & BASA & MF & 42 & $3.97 \pm 0.21$ & 129 & - & - & 0.62 & 94 \\
\hline $\begin{array}{l}\text { White-rumped } \\
\text { Sandpiper }\end{array}$ & $\begin{array}{l}\text { Calidris } \\
\text { fuscicollis }\end{array}$ & WRSA & $\mathrm{F}$ & 42 & $3.84 \pm 0.44$ & 96 & - & - & 0.46 & 69 \\
\hline $\begin{array}{l}\text { Pectoral } \\
\text { Sandpiper }\end{array}$ & $\begin{array}{l}\text { Calidris } \\
\text { melanotos }\end{array}$ & PESA & $\mathrm{F}$ & 69 & $3.94 \pm 0.30$ & 912 & $22 \pm 1.02$ & 44 & 0.63 & 697 \\
\hline $\begin{array}{l}\text { Semipalmated } \\
\text { Sandpiper }\end{array}$ & Calidris pusilla & SESA & MF & 26 & $3.86 \pm 0.41$ & 1678 & $19 \pm 1.05$ & 143 & 0.65 & 1210 \\
\hline $\begin{array}{l}\text { Western } \\
\text { Sandpiper }\end{array}$ & Calidris mauri & WESA & MF & 28 & $3.67 \pm 0.58$ & 574 & $20 \pm 0.97$ & 70 & 0.46 & 399 \\
\hline $\begin{array}{l}\text { Long-billed } \\
\text { Dowitcher }\end{array}$ & $\begin{array}{r}\text { Limnodromus } \\
\text { scolopaceus }\end{array}$ & LBDO & MF & 118 & $3.81 \pm 0.54$ & 171 & - & - & 0.48 & 99 \\
\hline $\begin{array}{l}\text { Red-necked } \\
\text { Phalarope }\end{array}$ & $\begin{array}{l}\text { Phalaropus } \\
\text { lobatus }\end{array}$ & RNPH & M & 34 & $3.83 \pm 0.45$ & 843 & $20 \pm 1.67$ & 57 & 0.53 & 533 \\
\hline $\begin{array}{l}\text { Red } \\
\text { Phalarope }\end{array}$ & $\begin{array}{l}\text { Phalaropus } \\
\text { fulicarius }\end{array}$ & REPH & M & 49 & $3.83 \pm 0.45$ & 1028 & $19 \pm 2.10$ & 77 & 0.70 & 859 \\
\hline
\end{tabular}

${ }^{\mathrm{a} B i p a r e n t a l}(\mathrm{MF})$, female-only (F) or male-only (M) incubation of the nest (Rodewald 2015). ${ }^{\mathrm{b}}$ For the incubating sex(es); this study. ${ }^{\mathrm{C}}$ Four subspecies of Dunlin occurred at our study sites: sakhalina (CHAU), pacifica (NOME, CAKR), arcticola (BARR, IKPI, COLV, PRBA, CARI) and hudsonia (CHUR, BURN, COAT, EABA, IGLO) (Cramp \& Simmons 1983, Miller et al. 2015).

Hobo Weather Station, U30 Series; Pocasset, MA, USA). For two sites with both types of data, temperatures from permanent and portable weather stations were highly correlated $(r>0.95$, slope $\approx$ 1.0). We used data from the permanent weather stations where available, as portable stations did not always collect data for the entire season. For the clutch size analysis, we averaged the daily temperatures during the estimated egg-laying period for each nest (1 day per egg) plus 1 week prior to nest initiation to include time needed for the uptake of nutrients for egg formation (Klaassen et al. 2001). For the analysis of incubation duration, we used the mean temperature during the incubation period. We used the mean temperature for each day in the analysis of daily survival rates of nests. Temperature was not correlated with timing of snowmelt $(r=0.006, P=0.212$; annual value of timing of snowmelt vs. mean daily temperature during the nest initiation period with site 
and year as random effects) because snow depth, cloud cover and rainfall also affect the timing and rate of snowmelt (Zhang et al. 1996, Stone et al. 2002).

We recorded the numbers of arvicoline rodents and predators observed per person-hour of fieldwork over the course of each summer in 2010 2014 as an index of local abundance (Hochachka et al. 2000). We did not have similar data for 2008 and 2009. Observations were recorded either as part of dedicated surveys or incidentally over the course of fieldwork during each day of the shorebird breeding season. The type of survey varied among sites but was consistent among years within each site. Observations for the BYLO field site were collected as part of a concurrent study (G. Gauthier unpubl. data). We included all species of lemmings and voles in the arvicoline group, and the primary avian (gulls Larus spp. and skuas Stercorarius spp.) and mammalian (Red Fox Vulpes vulpes and Arctic Fox Alopex lagopus) predators of shorebird nests (Liebezeit \& Zack 2008, McKinnon \& Bêty 2009). For arvicolines, we used the annual mean count per person-hour to categorize years within each site into three levels of relative abundance: low, moderate or high relative to other years. For predators, we evaluated avian and mammalian predators separately, and averaged the daily counts per person-hour across a rolling 7-day window to reduce the variance associated with daily chance encounters with predators. For the clutch size analysis, the 7-day window included 4 days of egg-laying, based on the modal clutch size and laying schedule (Norton 1972, Sandercock 1998), and 3 days prior to the egg-laying period. For the DSR analysis, for each day of the season, the 7 -day window included the focal day plus 3 days on either side. We did not test for effects of abundance of arvicolines or predators on incubation duration.

\section{Statistical models}

\section{Model structure}

We developed hierarchical models in a Bayesian framework to estimate effects of all covariates on each of the three reproductive traits after Weiser et al. (2017). In brief, we categorized clutch size as a binary variable: less than four eggs $(0)$ or four eggs (1) because our study species have a modal clutch size of four eggs (Rodewald 2015). We expressed incubation duration as the per cent difference from the median value for each taxon. The DSR model evaluated the cause-specific risk of failure due to predation, abandonment by the attending parents or other causes.

We included a taxon-specific linear effect of day-of-season on each component of fecundity (Weiser et al. 2017) and expanded on the previous model by testing two environmental covariates and three ecological covariates. We tested for linear and quadratic effects of the site-specific annual timing of snowmelt, air temperature during the relevant time window for each nest, a categorical effect of site-specific annual arvicoline rodent abundance and linear effects of site-specific indices of predator abundance (for avian and mammalian predators separately). We first centred each continuous covariate to the site-specific mean to examine how local variation affected shorebirds, assuming that the geographical distribution of each taxon was dictated by environmental and ecological conditions, and thus change in a covariate relative to the local mean would be more important than the absolute value. Next, we standardized each centred covariate to the mean and two standard deviations across all sites and years so that effect sizes were comparable among binary and continuous covariates (Gelman \& Hill 2007).

We estimated taxon-specific effects of covariates on the probability of laying the maximum clutch size of four eggs, duration of incubation and the daily probability of a nest surviving (DSR). Taxonspecific effect sizes were drawn from a single distribution per covariate with a varying-slopes model (Gelman \& Hill 2007, Weiser et al. 2017), as we expected taxa to respond to covariates in the same direction. The varying-slopes model allowed both the magnitude and the direction of the effect size to vary across taxa based on the available data. Within the DSR model, we tested for an effect of each covariate on the probability of a nest failing to predation $\left(p_{\text {pred }}\right)$ and the probability of a nest being abandoned ( $\left.p_{\text {aband }}\right)$. Sample sizes for each cause of failure were small relative to the sample of all nests in the DSR analysis, which reduced statistical power, so we estimated a single effect of each covariate for all taxa pooled on $p_{\text {pred }}$ and paband.

\section{Variable selection}

We aimed to identify and make inference from only the covariates that affected nesting performance, while eliminating variables with no 
measurable effect. Model selection in a Bayesian framework is an emerging field, and the most widely used metric of fit for Bayesian models, the deviance information criterion (DIC), is not necessarily appropriate for complex models (Hooten \& Hobbs 2015). Other metrics of fit such as stochastic search variable selection are not appropriate for a varying-slopes model. We therefore examined the $95 \%$ Bayesian credible interval (BCI) for each taxon-specific effect and concluded that a covariate was informative for a given taxon if the 95\% BCI did not include zero. For the models of clutch size and DSR, we first ran the full model including all covariates, then dropped covariates where the 95\% BCI overlapped zero for all taxa and re-ran the model including only informative covariates. If necessary, we repeated the variable elimination process until all remaining covariates had an effect different from zero for at least one taxon, which we took as our final model for each component of the nesting cycle. The full model was restricted to years when ecological covariates were recorded (2010-2014), but if inclusion of ecological covariates was not supported, we used the entire dataset for our final model (2008-2014).

\section{Model fitting}

To build the Bayesian models, we used a logit link for the models of clutch size and DSR (where possible values ranged from 0 to 1 ), and modelled incubation duration on the natural scale as the per cent difference from the median. We specified an uninformative uniform prior for the intercept in the interval -5 to 5 ; for models that used a logit link, this corresponded to the interval 0 to 1 on the natural scale. Each model included random effects of taxon, site and year nested within site on the intercept. We used uninformative normal priors with a zero mean and $s d=100$ for all random effects on the intercept. We used an uninformative prior distribution with a mean of zero and a standard deviation in the interval 0 to 7 for the effect of each temporal, environmental or ecological covariate.

We executed the Bayesian models in JAGS v. 4.0 (Plummer 2003) through the package 'runjags' (Denwood 2016) in R v. 3.3.1 (R Core Team 2017). We discarded estimates from an adaptation period (500 iterations for clutch size; 1000 for DSR) and a burn-in period (1000 iterations for clutch size; 2000 for DSR) to produce good mixing across four chains. We then ran each model for a further 3000 iterations and saved the output from every third iteration to avoid autocorrelation, resulting in 1000 saved iterations used to generate posterior distributions of parameters. For each model run, we checked that convergence was achieved as indicated by Gelman-Rubin statistics $<1.10$ for all estimates of model parameters (Brooks \& Gelman 2012).

\section{Parameter estimates}

We used the final model to generate estimates for the mean value of the response and the effect of each covariate, as well as the 95\% BCI from the posterior distribution for each estimate. In the DSR model, we also estimated nest survival to the end of the incubation period, calculated as DSR raised to the power of the exposure period (median number of days of incubation plus the egg-laying period) for each taxon, and recorded the mean and 95\% BCI from the posterior distribution. We predicted each response value across the observed range of each environmental or ecological covariate that had an effect on a given taxon to evaluate the magnitude and biological relevance of the effect.

\section{RESULTS}

Our dataset included 7418 nests of 17 taxa of shorebirds at 16 field sites (Table 1, Table S2; Fig. 2). Across all taxa, $88 \%$ of nests had a final clutch size of four eggs, $10 \%$ had three eggs, $2 \%$ had two and $<1 \%$ had one. Median incubation duration ranged from 19 days in Semipalmated Sandpipers and Red Phalaropes to 28 days in Grey Plovers. In total, $61 \%$ of nests hatched, 30\% failed and $9 \%$ had an unknown fate, with an overall mean DSR of 0.9772 (sd $=0.0064)$. For nests that failed, the modelled probability of failing to each cause was 0.94 for predation, 0.04 for abandonment and 0.01 for other causes of failure.

Environmental and ecological covariates showed wide ranges of variation both within and among our study sites (Figs S1-S4). Timing of snowmelt ranged from 3 May to 20 July across sites and years $\quad($ mean $=10$ June; within-site $\mathrm{sd}=$ 2-11 days; Fig. S1). Daily mean temperature ranged from -3.1 to $24.1^{\circ} \mathrm{C} \quad$ (mean $=7.0{ }^{\circ} \mathrm{C}$; within-site among-year $\mathrm{sd}=3.1-5.7^{\circ} \mathrm{C}$ ) and tended to increase as the nesting season progressed (Fig. S2). Of 47 site-year combinations with data for abundance of arvicoline rodents, 63\% were 
categorized as low abundance, $12 \%$ as moderate and $24 \%$ as high within each site. Sites at higher latitudes $\left(>70^{\circ} \mathrm{N}\right.$; Table S1) tended to have larger fluctuations in arvicoline abundance from year to year than did sites at lower latitudes (Fig. S3). Avian predators (mean weekly value $=5.59$ observations per person-hour, within-site among-year $s d=0.14-84.52)$ were observed more frequently than mammalian predators (mean $=0.03$, withinsite among-year sd $=0.002-0.102$; Fig. S4).

We found linear effects of three covariates on reproductive traits, with no evidence for quadratic effects (Tables S3 and S5; Fig. 3). Early snowmelt increased the probability of a four-egg clutch from 0.61 (latest snowmelt; $95 \% \mathrm{BCI}=0.37,0.82$ ) to 0.91 (earliest snowmelt; 95\% BCI $=0.79,0.88$ ) for Western Sandpipers (Figs 3a and 4a). The earliest value for snowmelt shortened the duration of incubation for arcticola Dunlin by 1 day
$(4.40 \% ; 95 \%$ BCI $=-6.83 \%,-1.90 \%)$ and for Red Phalaropes by 0.39 days (2.38\%; 95\% $\mathrm{BCI}=-4.35 \%,-0.35 \%$; Figs $3 \mathrm{~d}$ and $4 \mathrm{~d}$ ) relative to the latest snowmelt. Relative to the lowest temperatures that we observed, the highest temperatures during the egg-laying period increased the probability of a four-egg clutch from 0.60 (95\% $\mathrm{BCI}=0.33,0.82)$ to $0.93(95 \% \mathrm{BCI}=0.79,0.99)$ for Western Sandpipers and from $0.76 \quad(95 \%$ $\mathrm{BCI}=0.58,0.90)$ to $0.97(95 \% \mathrm{BCI}=0.91,0.99)$ for Red-necked Phalaropes, with positive trends for 12 of the 15 other taxa (Figs $3 \mathrm{~b}$ and $4 \mathrm{~b}$ ). The highest daily temperatures also increased DSR from $0.9640 \quad(95 \% \quad \mathrm{BCI}=0.9352,0.9819)$ to 0.9890 (95\% BCI $=0.9789$, 0.9950) for Semipalmated Sandpipers and from $0.9546 \quad(95 \%$ $\mathrm{BCI}=0.9132, \quad 0.9791) \quad$ to $0.9880 \quad(95 \%$ $\mathrm{BCI}=0.9745,0.9954$ ) for Western Sandpipers (Figs $3 \mathrm{e}$ and $4 \mathrm{e}$ ). Semipalmated Sandpipers were
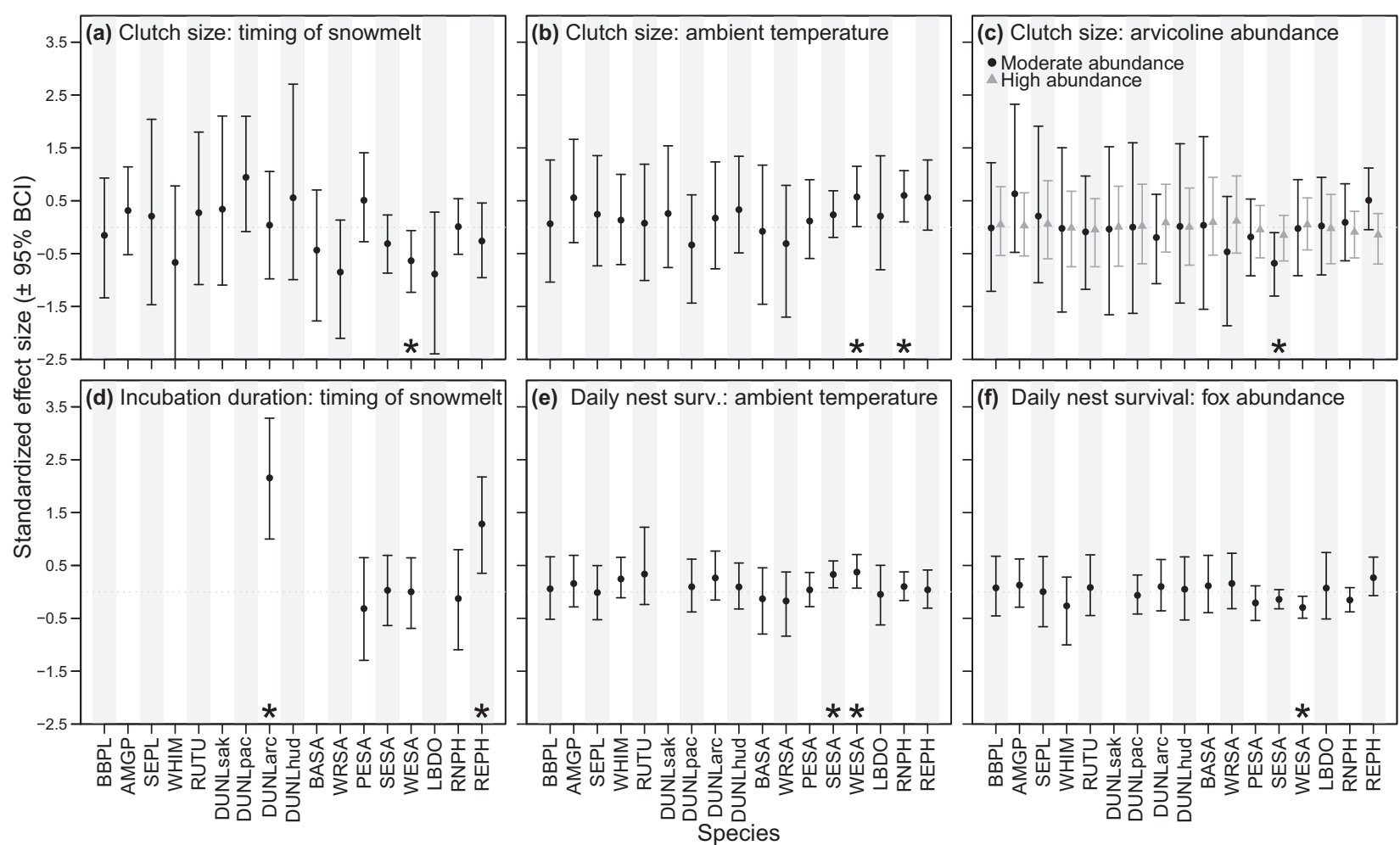

Figure 3. Standardized estimates of the taxon-specific effects of supported covariates on three reproductive traits for 17 taxa of shorebirds. Not all taxa were included in the analyses of incubation duration or daily nest survival rate. A positive value indicates larger clutch, longer incubation or higher DSR with later snowmelt than average $(a, d)$, higher temperatures $(b, e)$, the indicated abundance of arvicoline rodents relative to years with low abundance (c), or higher fox abundance (f). Quadratic effects were tested but were not supported. Error bars indicate 95\% Bayesian credible intervals (BCls) and asterisks indicate estimates where $95 \% \mathrm{BCls}$ did not overlap zero. Species codes are defined in Table 1. 

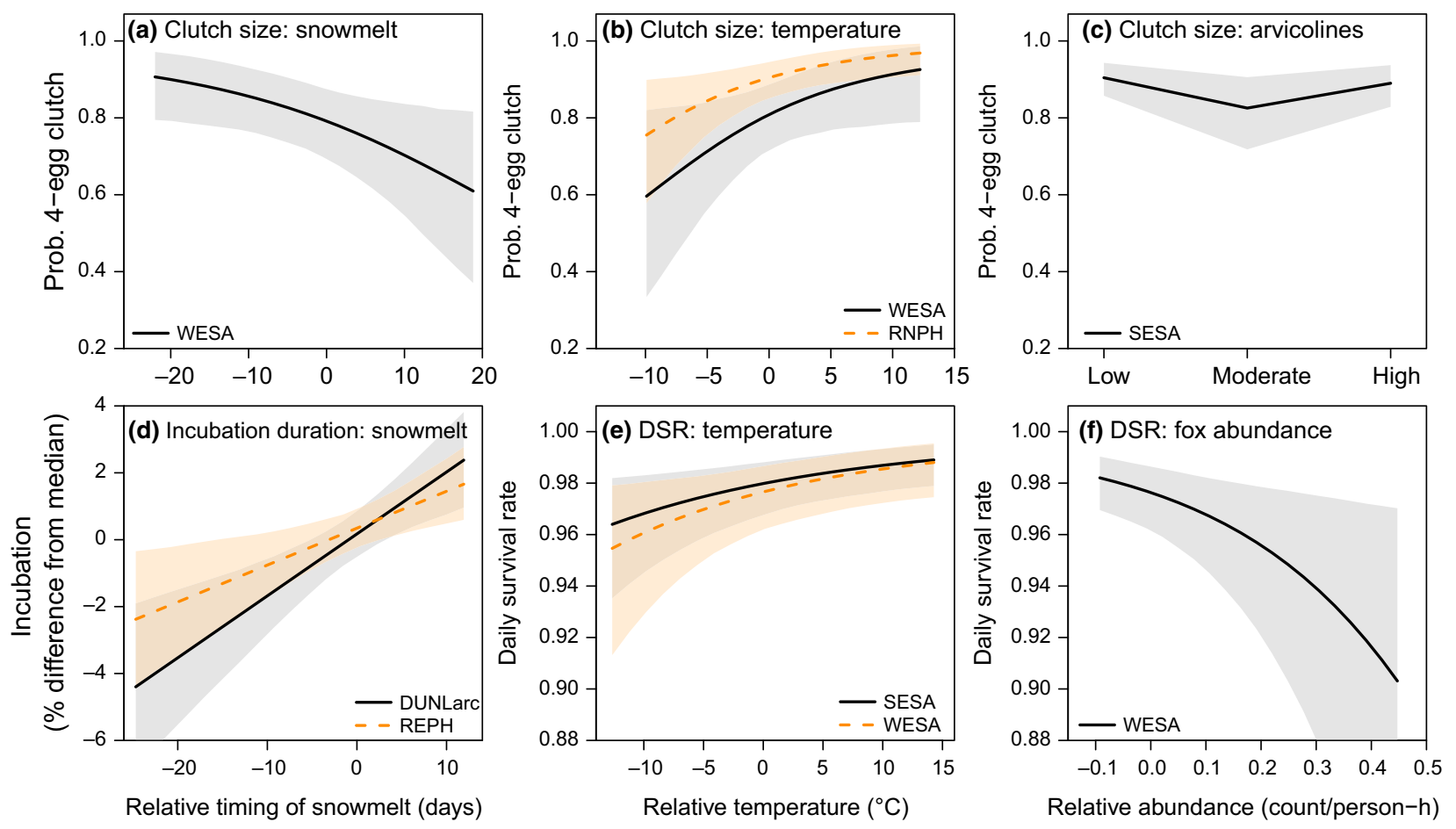

Figure 4. Relationships between reproductive traits and environmental covariates for each shorebird taxon where the $95 \%$ Bayesian credible interval $(\mathrm{BCl})$ for the covariate effect size did not overlap zero. Values on the horizontal axis are displayed on the natural scale (snowmelt: days; temperature: degrees Celsius; arvicoline abundance: low, moderate or high; fox abundance: number of individuals observed per person-hour) and centred to the population mean; a negative value indicates that timing of snowmelt was earlier $(a, d)$, temperature was lower (b,e) or fox abundance was lower $(\mathrm{f})$ than the local average. Shaded bands indicate $95 \% \mathrm{BCls}$ for the modelled relationships. [Colour figure can be viewed at http://onlinelibrary.wiley.com/journal/10.1111/(ISSN)1474-919X]

less likely to lay a four-egg clutch when arvicoline abundance was moderate $(P=0.83,95 \%$ $\mathrm{BCI}=0.72,0.91)$ than when abundance was high $(P=0.89, \quad 95 \% \quad \mathrm{BCI}=0.83, \quad 0.94) \quad$ or $\quad$ low $(P=0.90,95 \% \mathrm{BCI}=0.86,0.94$; Figs $3 \mathrm{c}$ and $4 \mathrm{c})$. Higher fox abundance reduced DSR from 0.9821 $(95 \% \mathrm{BCI}=0.9695,0.9903)$ when fox abundance was lowest, to $0.9031 \quad(95 \% \quad \mathrm{BCI}=0.7830$, 0.9702) when fox abundance was highest for Western Sandpipers (Figs $3 \mathrm{f}$ and $4 \mathrm{f}$ ). We found no support for effects of environmental or ecological covariates on rates of cause-specific nest failure.

\section{DISCUSSION}

Using a spatially distributed network of 16 Arctic field sites and controlling for previously demonstrated seasonal patterns (Weiser et al. 2017), we tested for effects of environmental and ecological covariates on three reproductive traits of 17 taxa of shorebirds. For 12 taxa, we found no effects of covariates on any reproductive trait. For the remaining five taxa, we found evidence that climate warming may increase reproductive effort and nest survival. We also found limited evidence for effects of predation risk on reproductive traits, where the abundance of alternative prey affected clutch size and high abundance of foxes negatively affected nest survival in one species.

Environmental conditions expected to occur under a regime of climate warming improved reproductive effort and nest success for five of the smallest taxa in our study (body mass $=26-58 \mathrm{~g}$ ). Western Sandpipers and Red-necked Phalaropes were more likely to lay the maximum clutch size of four eggs when snowmelt occurred early or when temperatures were high, relative to years with later snowmelt or lower temperatures. Incubation duration of two taxa, arcticola Dunlin and Red Phalaropes, was shorter when snowmelt occurred earlier than average. Nest survival rates of two species, Semipalmated and Western Sandpipers, also increased when temperatures were higher than average. Few nests in our dataset failed due to 
weather events, so the effect of temperature on nest survival may have been indirect and mediated by some other condition. In contrast to the smallest taxa, environmental effects on reproductive effort and nest survival were not evident in the larger species in our study. Bergmann's rule predicts that a warming environment will favour smaller-bodied species or individuals (Sheridan \& Bickford 2011), so larger species may not receive the same benefit as smaller species under changing conditions. Alternatively, smaller species may be more sensitive to environmental variation because they cannot use endogenous reserves to provision eggs and experience proportionally higher energetic demands of thermoregulation and incubation than larger birds (Mayfield 1979, McNab 1983, Schamel \& Tracy 1987, Piersma et al. 2003, Morrison \& Hobson 2004). However, it should be noted that our sample sizes were typically largest for the smallest species that we considered; larger species had larger territories and were thus more sparsely distributed in our study plots.

If the relationship between weather and reproductive output in small shorebirds is mediated by energetic demands, food availability is likely to play a role. Late snowmelt or lower temperatures reduce availability of invertebrate prey (Meltofte et al. 2007), and small shorebirds are primarily income breeders that rely on locally available food to produce eggs (Klaassen et al. 2001). Thus, higher availability of food during the egg-laying period could result in a higher probability of laying a full four-egg clutch. Arctic shorebirds also rely on local food sources to fuel incubation (Piersma et al. 2003), so incubation constancy may be improved in years of earlier snowmelt when more food is available. Similarly, male Red-necked Phalaropes show higher incubation constancy with higher ambient temperatures (English 2014), although there is no effect of temperature on bout length in species with biparental incubation (Bulla et al. 2016). More constant incubation reduces the number of days required for eggs fully to develop, thereby reducing the exposure period of the nest (Schamel \& Tracy 1987, Conway \& Martin 2000, Reneerkens et al. 2011). Higher incubation constancy also reduces movements of parents to and from the nest, thus improving nest success by reducing the chance of detection by a predator (Smith et al. 2012). The effect of temperature on DSR that we found in a few cases thus could have been mediated by parental behaviour that was in turn driven by physiological benefits from increased availability of food and lower thermoregulatory costs.

We found only one line of evidence for effects of alternative prey (arvicoline rodents) on reproductive traits: Semipalmated Sandpipers were less likely to lay a full clutch in years of moderate arvicoline abundance than in years with high or low abundance. The finding did not follow our prediction that clutch size would be smallest in years of low arvicoline abundance and largest in years of high abundance, which would be expected if birds adjusted clutch size based on abundance of alternative prey that would mitigate predation pressure. However, the estimated effect size was small. We also expected, but did not find, effects of arvicoline rodent abundance on survival rates of shorebird nests. Our results are thus consistent with previous studies of Arctic waterfowl that suggest that climatic conditions are more important than rodent abundance in driving reproductive performance (Juillet et al. 2012). However, the duration of our study (5-7 years per site) was short relative to the 3- to 5-year cycle of arvicoline populations. Our study therefore could have missed any other effects of alternative prey on reproductive traits of Arctic shorebirds, especially if lag effects would more accurately describe any relationships with arvicoline abundance.

Similarly, we unexpectedly found only one effect of predator abundance on nesting, such that nest survival of Western Sandpipers was reduced when fox abundance was high. We had expected more widespread effects of predators, as prior studies have shown that predation (or the risk of predation) causes a large proportion of nest failure in Arctic shorebirds (Liebezeit et al. 2009, Smith \& Wilson 2010, Smith et al. 2012). Predation was the main cause of nest failure in our study system, but our observational index of predator abundance may not accurately represent predation pressure (Liebezeit \& Zack 2008). In particular, any functional response of predators to prey availability may not be captured by counts of predators. Development of an improved index of predation risk that accounts for functional responses of predators, including changes in searching behaviour or demand for food associated with the predators' reproductive cycle (Wilson \& Bromley 2001), would be helpful for future studies of Arctic birds.

While we found positive effects of environmental covariates and negative effects of 
ecological covariates for a few shorebird species (five of 17 taxa), reproductive traits showed no relationship with any covariate for most taxa (12 of 17). Previous studies at individual sites in our network have reported relationships between breeding performance and environmental variables for additional species (Nol et al. 1997, Kwon et al. 2017), which could indicate regional variation in the effects of climate on Arctic shorebirds. It is also possible that as changes continue, effects of changing conditions may become more apparent for species that are adapted to historical conditions in the Arctic. In particular, predictions for the expected changes in abundance of predators and alternative prey should be quantified, and effects of those changes on shorebirds should be studied further, as predation is thought to play a large role in limiting fecundity of Arctic shorebirds. Studies of behavioural and phenological plasticity or genetic adaptation to changing conditions would also be useful to determine whether shorebirds can continue to withstand further changes even if there is currently little to no negative effect of changing variables. In addition, factors that we did not examine could have stronger long-term effects on Arctic-breeding shorebirds compared with the covariates in our study. For example, continuing changes in timing of emergence of invertebrate prey could reduce survival of shorebird chicks, depending on conditions that may vary geographically (Senner et al. 2017), and potentially offset the net effect of the improvements in the reproductive traits we measured. However, such phenological mismatch could be offset by thermal benefits of a warming environment (McKinnon et al. 2013). Moreover, climate change is expected dramatically to reduce the breeding range available to most Arctic shorebirds (up to 96\% loss; Wauchope et al. 2017), unless shorebirds are able to adapt or are more flexible in their choice of breeding conditions than currently recognized.

Together, our results suggest that climate warming may have neutral or positive effects on some stages of reproduction for most species of Arctic-breeding shorebirds. However, long-term threats on the breeding grounds could become important in the future and outweigh any shortterm positive effects. Understanding and conserving these highly migratory species will require continuing work to understand the responses of shorebirds to the changing climate and ecosystem.
E.L.W compiled the field data, designed and performed the statistical analyses and wrote the manuscript. B.K.S. assisted with design of analyses and preparation of the manuscript. R.B.L., S.C.B. and H.R.G. led development of standardized field protocols and coordinated field work. B.K.S., R.B.L., S.C.B., H.R.G. and all other authors, who are listed in alphabetical order, designed and conducted the field studies, contributed to interpreting the results and assisted with editing the manuscript. Major support for the ASDN was provided by the National Fish and Wildlife Foundation (grants 20100061-015, 2011-0032-014, 0801.12.032731 and 0801.13.041129), the Neotropical Migratory Bird Conservation Act (grants F11AP01040, F12AP00734 and F13APO535) and the Arctic Landscape Conservation Cooperative. Additional funding for participating field sites was provided by: Alaska Department of Fish and Game, Arctic Goose Joint Venture, Arctic National Wildlife Refuge, BP Exploration (Alaska) Inc., Bureau of Land Management, Canada Fund for Innovation, Canada Research Chairs, Cape Krusenstern National Monument grant, Centre for Wildlife Ecology at Simon Fraser University, Churchill Northern Studies Centre, Cornell University Graduate School Mellon Grant, Ducks Unlimited Canada, Environment and Climate Change Canada, FQRNT (Quebec), Government of Nunavut, Indigenous and Northern Affairs Canada, Kansas State University, Kresge Foundation, Liz Claiborne and Art Ortenberg Foundation, Manomet Center for Conservation Sciences, Mississippi Flyway Council, Murie Science and Learning Center grants, National Fish and Wildlife Foundation, National Park Service, National Science Foundation (Office of Polar Programs Grant ARC1023396 and Doctoral Dissertation Improvement Grant 11 10444), Natural Resources Canada (Polar Continental Shelf Program), Natural Sciences and Engineering Research Council of Canada (Discovery Grant and Northern Supplement), Neotropical Migratory Bird Conservation Act (grant 4073), Northern Studies Training Program, Selawik National Wildlife Refuge, Trust for Mutual Understanding, Université du Québec à Rimouski, University of Alaska Fairbanks, University of Colorado Denver, University of Missouri Columbia, University of Moncton, US Fish and Wildlife Service (Migratory Bird Management Division, Survey, Monitoring and Assessment Program, Alaska National Wildlife Refuge System's Challenge Cost Share Program and Avian Influenza Health and Influenza programmes), US Geological Survey (USGS) (Changing Arctic Ecosystem Initiative, Wildlife Program of the USGS Ecosystem Mission Area), and the W. Garfield Weston Foundation. Logistical support was provided by Arctic National Wildlife Refuge, Barrow Arctic Science Consortium, BP Exploration (Alaska) Inc., Kinross Gold Corporation, Umiaq LLC, Selawik National Wildlife Refuge (USFWS), ConocoPhillips Alaska Inc., Cape Krusenstern National Monument (National Park Service) and Sirmilik National Park (Parks Canada). We thank local communities and landowners, including the Ukpeagvik 
Iñupiat Corporation, the people of the Inuvialuit Settlement Region, Sitnasuak Native Corporation, the Kuukpik Corporation and the North Slope Borough for permitting us to conduct research on their lands. Animal handling, marking and monitoring procedures were approved by Environment and Climate Change Canada, Government of Nunavut, Kansas State University, National Park Service, Ontario Ministry of Natural Resources and Forestry, University of Alaska Fairbanks, University of Moncton, US Fish \& Wildlife Service and US Geological Survey. All applicable international, national and institutional guidelines for the care and use of animals were followed. We thank A. Tygart for assistance in compiling JAGS for use on the Beocat supercomputer at Kansas State University, D. Payer and S. Freeman for their work at Canning River, and H. Meltofte, P. Battley, B. Ross, J. Sutton, L. Martin and the Sandercock lab for comments on earlier drafts of the manuscript. We thank the many field assistants who were involved in data collection, especially field crew leaders K. Bennet, M. Burrell, J. Cunningham, E. D'Astous, S. Carvey, A. Doll, L. Pirie Dominix, K. Gold, A. Gottesman, K. Grond, P. Herzog, B. Hill, D. Hodgkinson, A.J. Johnson, D. Pavlik, M. Peck, L. Pollock, S. Sapora, B. Schwarz, F. Smith, H. M. Specht, M. VanderHeyden, B. M. Walker and B. Wilkinson. The findings and conclusions in this article are those of the author(s) and do not necessarily represent the views of the US Fish and Wildlife Service. Any use of trade names is for descriptive purposes only and does not imply endorsement by the US Government.

\section{REFERENCES}

ACIA. 2004. Impacts of a Warming Arctic: Arctic Climate Impact Assessment. Cambridge: Cambridge University Press.

Andres, B.A., Smith, P.A., Morrison, R.I.G., Gratto-Trevor, C.L., Brown, S.C. \& Friis, C.A. 2012. Population estimates of North American shorebirds, 2012. Wad. Study Group Bull 119: 178-194.

Angelstam, P., Lindström, E. \& Widén, P. 1984. Role of predation in short-term population fluctuations of some birds and mammals in Fennoscandia. Oecologia 62: 199-208.

Arnold, T.W. 1999. What limits clutch size in waders? J. Avian Biol. 30: 216-220.

Ballantyne, K. \& Nol, E. 2015. Localized habitat change near Churchill, Manitoba and the decline of nesting Whimbrels (Numenius phaeopus). Polar Biol. 38: 529-537.

Blomqvist, S., Holmgren, N., Åkesson, S., Hedenström, A. \& Pettersson, J. 2002. Indirect effects of lemming cycles on sandpiper dynamics: 50 years of counts from southern Sweden. Oecologia 133: 146-158.

Bolduc, E., Casajus, N., Legagneux, P., McKinnon, L., Gilchrist, H.H., Leung, M., Morrison, R.I.G., Reid, D., Smith, P.A., Buddle, C.M. \& Bêty, J. 2013. Terrestrial arthropod abundance and phenology in the Canadian Arctic: modeling resource availability for arctic-nesting insectivorous birds. Can. Entomol. 145: 155-170.
Brooks, S.P. \& Gelman, A. 2012. General methods for monitoring convergence of iterative simulations. J. Comput. Graph. Stat. 7: 434-455.

Brown, S.C., Gates, H.R., Liebezeit, J.R., Smith, P.A., Hill, B.L. \& Lanctot, R.B. (2014) Arctic Shorebird Demographics Network Breeding Camp Protocol, Version 5. U.S. Fish and Wildlife Service and Manomet Center for Conservation Sciences. Available at https://arcticdata.io/catalog/\#view/. https:// doi.org/10.18739/a2cd5m.

Bulla, M., Valcu, M., Dokter, A.M., Dondua, A.G., Kosztolányi, A., Rutten, A.L., Helm, B., Sandercock, B.K., Casler, B., Ens, B.J. \& Spiegel, C.S. 2016. Unexpected diversity in socially synchronized rhythms of shorebirds. Nature 540: 109-113.

CEN. 2016. Climate station data from Bylot Island in Nunavut, Canada, v. 1.6 (1992-2015). Nordicana D2, https://doi.org/ 10.5885/45039sl-ee76c1bdaadc4890.

Clements, J.F., Schulenberg, T.S., Iliff, M.J., Roberson, D., Fredericks, T.A., Sullivan, B.L. \& Wood, C.L. (2015) The eBird/Clements checklist of birds of the world: v2015. Downloaded from http://www.birds.cornell.edu/clementschecklist/ download/

Conway, C.J. \& Martin, T.E. 2000. Evolution of passerine incubation behavior: influence of food, temperature, and nest predation. Evolution 54: 670-685.

Cramp, S. \& Simmons, K.E.L. 1983. Handbook of the Birds of Europe, the Middle East and North Africa - The Birds of Western Palearctic, 3 edn. Oxford: Oxford University Press.

Denwood, M.J. 2016. runjags: An R package providing interface utilities, model templates, parallel computing methods and additional distributions for MCMC models in JAGS. J. Stat. Softw. 71: 1-25.

Drent, R.H. \& Daan, S. 1980. The prudent parent: energetic adjustments in avian breeding. Ardea 68: 225-252.

English, W.B. 2014. The evolutionary ecology of reproductive traits in the red-necked phalarope (Phalaropus lobatus). Thesis, Simon Frazer University.

English, W.B., Schamel, D., Tracy, D.M., Westneat, D.F. \& Lank, D.B. 2014. Sex ratio varies with egg investment in the Red-necked Phalarope (Phalaropus lobatus). Behav. Ecol. Sociobiol. 68: 1939-1949.

Gauthier, G., Bêty, J., Cadieux, M.-C., Legagneux, P., Doiron, M., Chevallier, C., Lai, S., Tarroux, A. \& Berteaux, D. 2013. Long-term monitoring at multiple trophic levels suggests heterogeneity in responses to climate change in the Canadian Arctic tundra. Philos. Trans. R. Soc. Lond. B Biol. Sci. 368: 20120482.

Gelman, A. \& Hill, J. 2007. Data Analysis Using Regression and Multilevel/Hierarchical Models. Cambridge: Cambridge University Press.

Gilg, O., Sittler, B. \& Hanski, I. 2009. Climate change and cyclic predator-prey population dynamics in the high Arctic. Glob. Change Biol. 15: 2634-2652.

Government of Canada. 2015. National Climate Archives. http://climate.weather.gc.ca/ (accessed 12 June 2015).

Hill, B.L. 2012. Factors Affecting Survival of Arctic-Breeding Dunlin (Calidris Alpina Arcticola) Adults and Chicks. Fairbanks: University of Alaska.

Hochachka, W.M., Martin, K., Doyle, F. \& Krebs, C.J. 2000. Monitoring vertebrate populations using observational data. Can. J. Zool. 78: 521-529. 
Hooten, M.B. \& Hobbs, N.T. 2015. A guide to Bayesian model selection for ecologists. Ecol. Monogr. 85: 3-28.

IPCC. 2013. Climate Change 2013: The Physical Science Basis. Contribution of Working Group $I$ to the Fifth Assessment Report of the Intergovernmental Panel on Climate Change. Cambridge, UK and New York: Cambridge University Press.

Jamieson, S.E., Ydenberg, R.C. \& Lank, D.B. 2014. Does predation danger on southward migration curtail parental investment by female Western Sandpipers? Anim. Migr. 2: 34-43.

Juillet, C., Choquet, R., Gauthier, G., Lefebvre, J. \& Pradel, R. 2012. Carry-over effects of spring hunt and climate on recruitment to the natal colony in a migratory species. $J$. Appl. Ecol. 49: 1237-1246.

Kausrud, K.L., Mysterud, A., Steen, H., Vik, J.O., Østbye, E., Cazelles, B., Framstad, E., Eikeset, A.M., Mysterud, I., Solhøy, T. \& Stenseth, N.C. 2008. Linking climate change to lemming cycles. Nature 456: 93-97.

Killengreen, S.T., Lecomte, N., Ehrich, D., Schott, T., Yoccoz, N.G. \& Ims, R.A. 2011. The importance of marine vs. human-induced subsidies in the maintenance of an expanding mesocarnivore in the arctic tundra. J. Anim. Ecol. 80: 1049-1060.

Klaassen, M., Lindström, A., Meltofte, H. \& Piersma, T. 2001. Arctic waders are not capital breeders. Nature 413: 794.

Kwon, E. 2016. Effects of climate change on the breeding ecology and trophic interactions of Arctic-Breeding Shorebirds. Thesis, Kansas State University.

Kwon, E., English, W.B., Weiser, E.L., Franks, S.E., Hodkinson, D.J., Lank, D.B. \& Sandercock, B.K. 2017. Delayed egg-laying and shortened incubation duration of Arctic-breeding shorebirds coincide with climate cooling. Ecol. Evol. Early View Article. https://doi.org/10.1002/ece3. 3733

Lanctot, R.B., Weiser, E.L., Sandercock, B.K. \& Brown, S.C. 2015. 2010-2014 Final report: Using a Network of Sites to Evaluate How Climate-mediated Changes in the Arctic Ecosystem are Affecting Shorebird Distribution, Ecology and Demography. Unpublished report by the US Fish and Wildlife Service, Kansas State University, and Manomet Center for Conservation Science.

Liebezeit, J.R. \& Zack, S. 2008. Point counts underestimate the importance of arctic foxes as avian nest predators: evidence from remote video cameras in arctic Alaskan oil fields. Arctic 61: 153-161.

Liebezeit, J.R., Smith, P.A., Lanctot, R.B., Schekkerman, H., Tulp, I., Kendall, S.J., Tracy, D.M., Rodrigues, R.J., Meltofte, H., Robinson, J.A. \& Gratto-Trevor, C. 2007. Assessing the development of shorebird eggs using the flotation method: species-specific and generalized regression models. Condor 109: 32-47.

Liebezeit, J.R., Kendall, S.J., Brown, S., Johnson, C.B., Martin, P., McDonald, T.L., Payer, D.C., Rea, C.L., Streever, B., Wildman, A.M. \& Zack, S. 2009. Influence of human development and predators on nest survival of tundra birds, Arctic Coastal Plain, Alaska. Ecol. Appl. 19: 1628-1644.

Liebezeit, J.R., Gurney, K.E.B., Budde, M., Zack, S. \& Ward, D. 2014. Phenological advancement in arctic bird species: relative importance of snow melt and ecological factors. Polar Biol. 37: 1309-1320.
Lima, S.L. 1987. Clutch size in birds: a predation perspective. Ecology 68: 1062-1070.

Lin, D.H., Johnson, D.R., Andresen, C. \& Tweedie, C.E. 2012. High spatial resolution decade-time scale land cover change at multiple locations in the Beringian Arctic (19482000s). Environ. Res. Lett. 7: 25502.

Mabee, T.J. 1997. Using eggshell evidence to determine nest fate of shorebirds. Wilson Bull 109: 307-313.

Mayfield, H.F. 1979. Red Phalaropes breeding on Bathurst Island. Living Bird 17: 7-39.

McCaffery, B.J. \& Ruthrauff, D.R. 2004. Spatial variation in shorebird nest success: Implications for inference. Wad. Study Group Bull 103: 67-70.

McKinnon, L. \& Bêty, J. 2009. Effect of camera monitoring on survival rates of High-Arctic shorebird nests. J. Field Ornithol. 80: 280-288.

McKinnon, L., Smith, P.A., Nol, E., Martin, J.L., Doyle, F.I., Abraham, K.F., Gilchrist, H.G., Morrison, R.I. \& Bêty, J. 2010. Lower predation risk for migratory birds at high latitudes. Science 327: 326-327.

McKinnon, L., Nol, E. \& Juillet, C. 2013. Arctic-nesting birds find physiological relief in the face of trophic constraints. Sci. Rep. 3: 1816.

McKinnon, L., Berteaux, D. \& Bêty, J. 2014. Predatormediated interactions between lemmings and shorebirds: a test of the alternative prey hypothesis. Auk 131: 619628.

McNab, B.K. 1983. Energetics, body size, and the limits to endothermy. J. Zool. 199: 1-29.

Meltofte, H., Piersma, T., Boyd, H., McCaffery, B., Ganter, B., Golovnyuk, V.V., Graham, K., Gratto-Trevor, C.L., Morrison, R.I.G., Nol, E., Rösner, H.-U., Schamel, D., Schekkerman, H., Soloviev, M.Y., Tomkovich, P.S. Tracy, D.M., Tulp, I. \& Wennerberg, L. 2007. Effects of climate variation on the breeding ecology of Arctic shorebirds. In: Meddelelser Om Gronland Bioscience 59: $\mathrm{p}$. 48. Copenhagen: Danish Polar Center.

Meltofte, H., Høye, T.T. \& Schmidt, N.M. 2008. Effects of food availability, snow and predation on breeding performance of waders at Zackenberg. Adv. Ecol. Res. 40: 325-343.

Miller, M.P., Haig, S.M., Mullins, T.D., Ruan, L., Casler, B., Dondua, A., Gates, H., Johnson, J.M., Kendall, S., Tomkovich, P.S. \& Tracy, D. 2015. Intercontinental genetic structure and gene flow in Dunlin (Calidris alpina), a potential vector of avian influenza. Evol. Appl. 8: 149-171.

Morrison, R.I.G. \& Hobson, K.A. 2004. Use of body stores in shorebirds after arrival on High-Arctic breeding grounds. Auk 121: 333-344

NAS. 2003. Cumulative Environmental Effects of oil and gas Activities on Alaska's North Slope. National Research Council of the National Academies. Washington, DC: National Academies Press.

National Centers for Environmental Information. 2015. Quality Controlled Local Climatological Data (QCLCD). http://www.ncdc.noaa.gov/data-access/land-based-station-da ta/land-based-datasets/quality-controlled-local-climatologicaldata-qclcd (accessed 12 June 2015).

National Ice Center. 2008. IMS Daily Northern Hemisphere Snow and Ice Analysis at $1 \mathrm{~km}, 4 \mathrm{~km}$, and $24 \mathrm{~km}$ Resolutions, Version 1. [4 km resolution]. Updated daily. https://doi.org/10.7265/n52r3pmc (accessed 9 June 2015). 
Nol, E., Blanken, M.S. \& Lynn, L. 1997. Sources of variation in clutch size, egg size and clutch completion dates of Semipalmated Plovers in Churchill, Manitoba. Condor 99: 389-396.

Norton, D.W. 1972. Incubation schedules of four species of calidridine sandpipers at Barrow, Alaska. Condor 74: 164 176.

Piersma, T. \& Lindström, A. 2004. Migrating shorebirds as integrative sentinels of global environmental change. Ibis 146: 61-69.

Piersma, T., Lindström, A., Drent, R.H., Tulp, I., Jukema, J., Morrison, R.I.G., Reneerkens, J., Schekkerman, H. \& Visser, G.H. 2003. High daily energy expenditure of incubating shorebirds on High Arctic tundra: a circumpolar study. Funct. Ecol. 17: 356-362.

Plummer, M. 2003. JAGS: a program for analysis of Bayesian graphical models using Gibbs sampling. In Hornik, K., Leisch, F. \& Zeileis, A. (eds) Proceedings of the 3rd International Workshop on Distributed Statistical Computing (DSC 2003). Vienna: Technische Universität Wien.

R Core Team. 2017. R: A Language and Environment for Statistical Computing. Vienna: R Foundation for Statistical Computing. https://www.R-project.org/. Version 3.3.3.

Reneerkens, J., Grond, K., Schekkerman, H., Tulp, I. \& Piersma, T. 2011. Do uniparental Sanderlings Calidris alba increase egg heat input to compensate for low nest attentiveness? PLoS One 6: e16834.

Rodewald, P. (ed) 2015. The Birds of North America Online. Ithaca, NY: Cornell Laboratory of Ornithology. http://bna.bird s.cornell.edu/BNA/

Saalfeld, S.T. \& Lanctot, R.B. 2015. Conservative and opportunistic settlement strategies in Arctic-breeding shorebirds. Auk 132: 212-234.

Sandercock, B.K. 1998. Chronology of nesting events in Western and Semipalmated Sandpipers near the Arctic Circle. J. Field Ornithol. 69: 235-243.

Sandercock, B.K., Lank, D.B. \& Cooke, F. 1999. Seasonal declines in the fecundity of arctic-breeding sandpipers: different tactics in two species with an invariant clutch size. J. Avian Biol. 30: 460-468.

Schamel, D. \& Tracy, D.M. 1987. Latitudinal trends in breeding Red Phalaropes. J. Field Ornithol. 58: 126-134.

Schekkerman, H., Tulp, I., Piersma, T. \& Visser, G.H. 2003. Mechanisms promoting higher growth rate in arctic than in temperate shorebirds. Oecologia 134: 332-342.

Sénéchal, É., Bêty, J., Gilchrist, H.G., Hobson, K.A. \& Jamieson, S.E. 2011. Do purely capital layers exist among flying birds? Evidence of exogenous contribution to arctic-nesting common eider eggs. Oecologia 165: 593604.

Senner, N.R., Stager, M. \& Sandercock, B.K. 2017. Ecological mismatches are moderated by local conditions for two populations of a long-distance migratory bird. Oikos 126: 61-72.

Sheridan, J.A. \& Bickford, D. 2011. Shrinking body size as an ecological response to climate change. Nat. Clim. Change 1: 401-406.

Smith, P.A. \& Wilson, S. 2010. Intraseasonal patterns in shorebird nest survival are related to nest age and defence behaviour. Oecologia 163: 613-624.

Smith, P.A., Tulp, I., Schekkerman, H., Gilchrist, H.G. \& Forbes, M.R. 2012. Shorebird incubation behaviour and its influence on the risk of nest predation. Anim. Behav. 84: 835-842.

Sovada, M.A., Anthony, R.M. \& Batt, B.D.J. 2001. Predation on waterfowl in arctic tundra and prairie breeding areas: a review. Wildl. Soc. Bull. 29: 6-15.

Stehn, R.A., Larned, W.W. \& Platte, R.M. 2013. Analysis of Aerial Survey Indices Monitoring Waterbird Populations of the Arctic Coastal Plain, Alaska, 1986-2012. Anchorage and Soldotna: USFWS, Migratory Bird Management.

Stickney, A.A., Obritschkewitsch, T. \& Burgess, R.M. 2014. Shifts in fox den occupancy in the greater Prudhoe Bay area, Alaska. Arctic 67: 196-202.

Stone, R.S., Dutton, E.G., Harris, J.M. \& Longenecker, D. 2002. Earlier spring snowmelt in northern Alaska as an indicator of climate change. J. Geophys. Res. Atmos. 107: ACL 10-1-ACL 10-13.

Studds, C.E., Kendall, B.E., Murray, N.J., Wilson, H.B., Rogers, D.I., Clemens, R.S., Gosbell, K., Hassell, C.J., Jessop, R., Melville, D.S., Milton, D.A., Minton, C.D.T., Possingham, H.P., Riegen, A.C., Straw, P., Woehler, E.J. \& Fuller, R.A. 2017. Rapid population decline in migratory shorebirds relying on Yellow Sea tidal mudflats as stopover sites. Nat. Commun. 8: 14895.

Summers, R.W., Underhill, L.G. \& Syroechkovski, E.E., Jr 1998. The breeding productivity of dark-bellied Brent Geese and Curlew Sandpipers in relation to changes in the numbers of arctic foxes and lemmings on the Taimyr Peninsula, Siberia. Ecography 21: 573-580.

Thomas, G.H., Lanctot, R.B. \& Székely, T. 2006. Can intrinsic factors explain population declines in North American breeding shorebirds? A comparative analysis. Anim. Conserv. 9: 252-258.

Tulp, I. \& Schekkerman, H. 2008. Has prey availability for Arctic birds advanced with climate change? Hindcasting the abundance of tundra arthropods using weather and seasonal variation. Arctic 61: 58-60.

Wauchope, H.S., Shaw, J.D., Varpe, Ø., Lappo, E.G., Boertmann, D., Lanctot, R.B. \& Fuller, R.A. 2017. Rapid climate-driven loss of breeding habitat for Arctic migratory birds. Glob. Change Biol. 23: 1085-1094.

Weiser, E.L., Brown, S.C., Lanctot, R.B., Gates, H.R., Abraham, K., Bentzen, R.L., Bêty, J., Boldenow, M.L., Brook, R., Donnelly, T.F., English, W.B., Flemming, S., Franks, S.E., Gilchrist, H.G., Giroux, M.A., Johnson, A., Kennedy, L.V., Koloski, L., Kwon, E., Lamarre, J.F., Lank, D.B., Lecomte, N., Liebezeit, J.R., McKinnon, L., Nol, E., Perz, J., Rausch, J., Robards, M., Saalfeld, S.T., Senner, N.R., Smith, P.A., Soloviev, M., Solovyeva, D., Ward, D.H., Woodard, P.F. \& Sandercock, B.K. 2017. Life-history tradeoffs revealed by seasonal declines in reproductive traits of 21 species of Arctic-breeding shorebirds. J. Avian Biol. (in press). https://doi.org/10.1111/jav.01531

Wilson, D.J. \& Bromley, R.G. 2001. Functional and numerical responses of predators to cyclic lemming abundance: effects on loss of goose nests. Can. J. Zool. 79: 525-532.

Zhang, T., Stamnes, K. \& Bowling, S.A. 1996. Impact of clouds on surface radiative fluxes and snowmelt in the Arctic and Subarctic. J. Clim. 9: 2110-2123.

Received 7 July 2017; revision accepted 5 December 2017. Associate Editor: Phil Battley. 


\section{SUPPORTING INFORMATION}

Additional Supporting Information may be found in the online version of this article:

Table S1. Study sites in the Arctic Shorebird Demographics Network, ordered from west to east.

Table S2. Number of shorebird nests included in the final models for each taxon and site.

Table S3. Effect sizes and BCIs for covariates from the full model, which included all covariates, for each reproductive trait.

Table S4. Intercepts and estimates of standard deviations of random effects from the full model for each reproductive trait, estimated across all taxa.

Table S5. Effect sizes and BCIs for covariates included in the final model, including only informative covariates, for each reproductive trait.
Table S6. Intercepts and estimates of standard deviations of random effects from the final model for each reproductive trait, estimated across all taxa.

Figure S1. First snow-free day for each year at each study site.

Figure S2. Mean daily temperatures $\left({ }^{\circ} \mathrm{C}\right)$ over the shorebird breeding season at 14 field sites in the Arctic Shorebird Demographics Network, 2008-2014.

Figure S3. Observations of arvicoline rodents per person-hour at each field site in the Arctic Shorebird Demographics Network.

Figure S4. Daily observations of avian predators (gulls and jaegers; dotted line) and foxes (solid line) at each field site in the Arctic Shorebird Demographics Network. 